\title{
Association of peripheral leukocyte telomere length and its variation with pancreatic cancer and colorectal cancer risk in Chinese population
}

\author{
Rui Zhang ${ }^{1}$, Jian Zhao ${ }^{1}$, Jian $X^{1}{ }^{1}$, Fang Liu ${ }^{1}$ \\ ${ }^{1}$ Department of Colorectal surgery, Liaoning cancer hospital \& institute, Shenyang, Liaoning Province, 110042, P.R. China \\ Correspondence to: Fang Liv, email: liufangsy@163.com \\ Keywords: cancer, telomere length, LTL, TLV, risk
}

Received: March 20, $2016 \quad$ Accepted: April 27, $2016 \quad$ Published: May 21, 2016

ABSTRACT

There is increasing evidence supporting the role of telomeres in cancer pathogenesis. However, limited studies have investigated the association between telomere length features and risk of pancreatic cancer and colorectal cancer (CRC), and little was conducted in Asians. To help clarify this issue, We measured relative peripheral leukocytes telomere length (LTL) and telomere length variation (TLV) in a prospective study of 900 pancreatic cancer cases, 300 CRC cases, and 900 controls. Both subjects with longer LTL (quartile 4: adjusted OR=1.51, 95\% CI: 1.141.99, $P=0.004$ ) and shorter LTL (quartile 1: adjusted $O R=3.12,95 \%$ CI: 1.89-5.14, $\left.P=8.50 \times 10^{-6}\right)$ showed increased risk of pancreatic cancer. A linear increased risk was detected For TLV (adjusted $O R=1.60,95 \% C I$ : 1.14-2.24, $P=0.006$ ). We also identified significant interaction for relative $L T L, T L V$ on pancreatic cancer risk ( $P$ interaction $=0.009$ ). Significant relationship between shorter RTL and increased CRC risk were also detected. This findings provide insights into telomere dynamics and highlight the complex relationship between relative LTL, TLV and cancer risk.

\section{INTRODUCTION}

The incidence of pancreatic cancer and colorectal cancer (CRC) has been increasing for several decades in Chinese population. Pancreatic cancer ranks the fifth leading cause of worldwide cancer death and the fourth leading cause of cancer mortality in the U.S, with an estimated new cases of 48,960 in 2015, and over 40,560 were estimated to die from the disease, while CRC ranks the fourth most common cause of cancer death [1-3]. According to a report of National Office for Cancer Prevention and Control of China, the prevalence of pancreatic cancer has risen up to 17.8 / 1,000 males, and $13.7 / 1,000$ females [4]. It is likely that a lack of effective screening methods to detect early disease contributes to its low 5-year survival rate, as few biomarkers have been identified to detect pancreatic cancer and CRC [5-7]. This makes pancreatic cancer the most deadly cancer worldwide, with a 5-year relative survival of less than 5\% [8-10]. Although many risk factors includes smoking, alcohol consumption, preexisting diabetes mellitus, obesity, and family history of cancer has been established, these factors, which can provide only a very weak prediction of an individual's pancreas cancer and CRC risk, can only account for a modest proportion of pancreatic cancer and CRC occurrences [11-13].

Telomere length and telomere erosion has been strongly implicated in the molecular biology of many cancers, including pancreatic cancer and CRC [14-17]. When telomere lengths become critically short, the process of cell senescence is initiated, resulting in cell-cycle arrest or apoptosis in normal cells [18-21]. Epidemiological studies have also shown that peripheral leukocytes telomere length (LTL) correlates with the incidence of major chronic diseases [14, 22-26]. LTL has become a biomarker of biological ageing and risk of age-related diseases, like cancers, cardiovascular disease and diabetes [26, 27]. So far, only three studies have investigated circulating LTL and risk of pancreatic cancer [12, 28, 29], while none of them were conducted in Asians. Additionally, recent studies also showed that telomere length variation (TLV) across all chromosomal ends, which could increase chromosome 
instability and poor clinical outcome, contributed to the risk of bladder cancer [30]. To further clarify the association between LTL, TLV and pancreatic cancer and CRC development, we performed this nested case-control study to examine the degree of association between LTL, TLV and risk of pancreatic cancer and $\mathrm{CRC}$.

\section{RESULTS}

\section{Characteristics of study population}

We measured the LTL in 900 pancreatic cancer cases, $300 \mathrm{CRC}$ cases and in 900 matched control subjects recruited in the context of the prospective CCPSAPP study. The distribution of relevant baseline characteristics of cases and controls is shown in Table 1. There were no significant differences in the distributions of age, gender, BMI, and infection of diabetes. The pancreatic cancer cases were significantly more likely than the controls to be smokers, drinkers, and patients of hypertension (All $\mathrm{P}$ value $<0.05$ ). Table 2 presents the overall case-control comparison of telomere features and stratified comparisons by age, gender. The pancreatic cases have significantly larger TLV, compared with the healthy controls. Age was inversely related to LTL, among the cases as well as among the healthy controls. While age was positively related to TLV. With respective to gender, women are likely have longer relative LTL and smaller TLV.

\section{Association between relative LTL, TLV and risk of pancreatic cancer}

Unconditional logistic regression analysis was used to evaluate the association between relative LTL, TLV and pancreatic cancer risk. As shown in Table 3, significant trend was detected for associations between relative LTL, TLV and risk of pancreatic cancer $(\mathrm{P}<0.01)$. For relative LTL, the third quartile was set as the reference. Both subjects with longer LTL (quartile 4: adjusted $\mathrm{OR}=1.51$, 95\% CI: 1.14-1.99, $\mathrm{P}=0.004$ ) and longer LTL (quartile 1: adjusted $\mathrm{OR}=3.12,95 \% \mathrm{CI}: 1.89-5.14, \mathrm{P}=8.50 \times 10^{-6}$ ) showed increased risk of pancreatic cancer. When analyzed as a continuous variable, a significantly increased risk was identified for short relative LTL (adjusted $\mathrm{OR}=1.50,95 \% \mathrm{CI}: 1.12-2.01, \mathrm{P}=0.007)$. For TLV, a linear increased risk was detected (adjusted $\mathrm{OR}=1.60$, 95\% CI: 1.14-2.24, $\mathrm{P}=0.006$ ). Compared with quartile 1 , both quartile 3 (adjusted $\mathrm{OR}=2.52$, 95\% CI: 1.27-4.99, $\mathrm{P}=0.008$ ) and quartile 4 (adjusted $\mathrm{OR}=4.27,95 \% \mathrm{CI}$ : 1.87 $9.75, \mathrm{P}=5.67 \times 10^{-4}$ ) showed statistically significant trend.

\section{Joint effects of relative LTL, TLV on pancreatic cancer and CRC risk}

To assess if combinations of relative LTL and TLV increased the risk stratification for pancreatic cancer and
CRC, we used the median value of control subjects as cutoff points to create comparison groups. As shown in Table 4, significant interaction was detected for relative LTL, TLV on pancreatic cancer risk $\left(\mathrm{P}_{\text {interaction }}=0.009\right)$. Compared to subjects with longer LTL and smaller TLV, subjects carrying shorter LTL and larger TLV exhibited a 1.38 -fold increased risk of pancreatic cancer $(\mathrm{OR}=1.38$; 95\% CI, 1.04-1.82; $\mathrm{P}=0.023$ ). However, we didn't find any significant interaction for CRC risk (data not shown).

\section{Association between relative LTL and risk of colorectal cancer}

To enhance our founding, we also replicated the association in a case-control study of colorectal cancer. As shown in Table 5, significant relationship between shorter RTL and increased CRC risk were detected (adjusted $\mathrm{OR}=1.27,95 \% \mathrm{CI}: 1.07-1.51, \mathrm{P}=0.007)$.

\section{DISCUSSION}

In this study, we conducted a nested case-control study in a Chinese population and evaluated the relationships between relative LTL, TLV and risk of pancreatic cancer and CRC. Our results showed that either short or extreme long telomere length were associated with an increased risk of pancreatic cancer. TLV was linearly associated with increased risk of pancreatic cancer. We also found significant interaction for relative LTL, TLV on pancreatic cancer risk. We also found that shorter RTL was associated with increased CRC risk. These findings provide novel epidemiological evidence for the effect of telomeres on the development of pancreatic cancer and CRC. To the best of our knowledge, this study should be the first study which aims to evaluate the association of telomere features and risk of pancreatic cancer in Asians.

Telomere length, a putative marker of biological age that have a key role in various cellular processes such as control of chromosomal stability, regulation of cell growth, and the proper segregation of chromosomes to daughter cells, has been identified to be associated with cancer development for a long time [15, 31-36]. Previous studies have produced inconsistent results and been hindered by being based on measurements from telomeres that were already exposed to cancer and treatments [37]. In 1997, Kobitsu et al first explore the relationship between shortened telomere length and increased telomerase activity in hamster pancreatic duct adenocarcinomas and cell lines [38]. van Heek et al also reported that telomere shortening was nearly universal in pancreatic intraepithelial neoplasia [39]. In this context, only three studies, including one case-control study which found short telomeres and extremely long telomeres in peripheral blood are associated with an increased risk for pancreatic cancer [12], and two nested case-control studies which presented the inconsistent results [28, 29]. 
Table 1: Baseline characteristics of pancreatic cancer cases and controls

\begin{tabular}{lccc}
\hline Variables & Cases $(\mathbf{N}=\mathbf{9 0 0})$ & Controls $(\mathbf{N}=\mathbf{9 0 0})$ & $\boldsymbol{P}$ value \\
\hline Age $($ years $)$ & $54.0 \pm 4.11$ & $54.2 \pm 4.19$ & 0.307 \\
BMI $\left(\mathrm{kg} / \mathrm{m}^{2}\right)$ & $26.1 \pm 3.1$ & $25.9 \pm 2.9$ & 0.158 \\
Gender & & & \\
$\quad$ Male & $409(45.4 \%)$ & $402(44.7 \%)$ & 0.740 \\
Female & $491(44.6 \%)$ & $498(45.3 \%)$ & \\
Ever smokers & $317(35.2 \%)$ & $264(29.3 \%)$ & $\mathbf{0 . 0 0 8}$ \\
Ever drinkers & $371(41.2 \%)$ & $295(32.8 \%)$ & $\mathbf{P}<\mathbf{0 . 0 0 1}$ \\
Diabetes & & & 0.114 \\
$\quad$ Yes & $387(43.0 \%)$ & $354(39.3 \%)$ & \\
No & $513(57.0 \%)$ & $546(60.7 \%)$ & $\mathbf{P}<\mathbf{0 . 0 0 1}$ \\
Hypertension & & $403(44.8 \%)$ & \\
Yes & $537(59.7 \%)$ & $497(55.2 \%)$ & \\
No & $363(40.3 \%)$ & & \\
\hline
\end{tabular}

Table 2: Case-control comparison of telomere features

\begin{tabular}{lccc}
\hline Telomere features & Cases mean (SD) & Controls mean (SD) & P value \\
\hline All subjects, N & 900 & 900 & 0.054 \\
Relative LTL & $1.49(0.21)$ & $1.51(0.23)$ & $\mathrm{P}<0.001$ \\
TLV & $60.1(9.8)$ & $56.2(10.1)$ & \\
Age $>60, \mathrm{~N}$ & 398 & 410 & 0.858 \\
Relative LTL & $1.45(0.35)$ & $1.47(0.31)$ & $\mathrm{P}<0.001$ \\
TLV & $63.2(11.4)$ & $59.8(10.9)$ & \\
Age $\leq 60, \mathrm{~N}$ & 502 & 490 & 0.250 \\
Relative LTL & $1.52(0.25)$ & $1.54(0.27)$ & $\mathrm{P}<0.001$ \\
TLV & $58.5(9.1)$ & $54.3(9.5)$ & 0.327 \\
Male & 409 & 402 & $\mathrm{P}<0.001$ \\
Relative LTL & $1.48(0.31)$ & $1.50(0.37)$ & \\
TLV & $60.9(10.2)$ & $56.7(11.2)$ & 0.280 \\
Female & 491 & 498 & $\mathrm{P}<0.001$ \\
Relative LTL & $1.50(0.31)$ & $1.52(0.27)$ & $56.1(9.0)$ \\
TLV & $59.2(8.9)$ & & \\
\hline
\end{tabular}

However, none of the studies was conducted in Asians, not to say Chinese. Thus, to provide the evidence for the association between the telomere features and risk of pancreatic cancer in Asians, we conducted this study.

Telomeres are the end caps of chromosomes and are composed of telomeric proteins and hexamer repeats of DNA (TTAGGG) that serve to protect the integrity of the DNA sequence during cell division [40]. Our findings suggested that either short or extreme long telomere length were associated with an increased risk of pancreatic cancer. This was similar to the conclusion of Skinner et al [12], although the limited sample size and the study design of case-control study. Lynch et al [22] identified that longer telomere length was significantly associated with increased pancreatic cancer risk (continuous $\mathrm{OR}=1.26$, 95\% CI 5 1.09-1.46), while Campa's results don't support 
Table 3: Associations between relative LTL, TLV and pancreatic cancer risk

\begin{tabular}{|c|c|c|c|c|}
\hline \multirow{2}{*}{ Variables } & \multicolumn{2}{|c|}{$\operatorname{Model~A}^{1}$} & \multicolumn{2}{|c|}{ Model B ${ }^{2}$} \\
\hline & OR $(95 \%$ CI $)$ & $\boldsymbol{P}$ & OR $(95 \%$ CI $)$ & $\boldsymbol{P}$ \\
\hline \multicolumn{5}{|l|}{ Relative LTL } \\
\hline Quartile 4 & $1.49(1.13-1.97)$ & 0.005 & $1.51(1.14-1.99)$ & 0.004 \\
\hline Quartile 3 & Reference & & Reference & \\
\hline Quartile 2 & $1.29(0.98-1.71)$ & 0.073 & $1.30(0.98-1.72)$ & 0.069 \\
\hline Quartile 1 & $3.10(1.84-5.21)$ & $2.00 \times 10^{-5}$ & $3.12(1.89-5.14)$ & $8.50 \times 10^{-6}$ \\
\hline Continuous & $1.49(1.11-2.00)$ & 0.008 & $1.50(1.12-2.01)$ & 0.007 \\
\hline \multicolumn{5}{|l|}{ TLV } \\
\hline Quartile 1 & Reference & & Reference & \\
\hline Quartile 2 & $1.80(0.98-3.32)$ & 0.060 & $1.79(0.96-3.32)$ & 0.065 \\
\hline Quartile 3 & $2.56(1.25-5.23)$ & 0.010 & $2.52(1.27-4.99)$ & 0.008 \\
\hline Quartile 4 & $4.31(1.71-10.89)$ & $2.01 \times 10^{-3}$ & $4.27(1.87-9.75)$ & $5.67 \times 10^{-4}$ \\
\hline Continuous & $1.65(1.13-2.15)$ & 0.007 & $1.60(1.14-2.24)$ & 0.006 \\
\hline
\end{tabular}

${ }^{1}$ Crude ORs.

${ }^{2}$ Adjusted for age, gender, smoking status, drinking status, hypertension, body mass index (BMI) and diabetes.

Table 4: Joint effects of relative LTL, TLV on pancreatic cancer risk

\begin{tabular}{|c|c|c|c|c|c|c|}
\hline \multirow{3}{*}{ Variables } & \multicolumn{6}{|c|}{ Relative LTL } \\
\hline & \multicolumn{3}{|c|}{ Long } & \multicolumn{3}{|c|}{ Short } \\
\hline & Case & Control & OR(95\% CI)* & Case & Control & OR(95\% CI $)^{*}$ \\
\hline \multicolumn{7}{|l|}{ TLV } \\
\hline short & 167 & 200 & 1.00 (reference) & 238 & 250 & $1.14(0.87-1.49)$ \\
\hline \multirow[t]{2}{*}{ long } & 261 & 247 & $1.26(0.97-1.65)$ & 234 & 203 & $1.38(1.04-1.82)$ \\
\hline & \multicolumn{6}{|c|}{$P$ for interaction $=\mathbf{0 . 0 0 9}$} \\
\hline
\end{tabular}

Table 5: Association between telomere length and colorectal cancer risk

\begin{tabular}{lcccc}
\hline Telomere length & Cases & Controls & Adjusted OR & P value \\
\hline 3rd tertile & 75 & 300 & 1.00 (reference) & \\
2nd tertile & 101 & 300 & $1.34(0.96-1.89)$ & 0.085 \\
$1^{\text {st }}$ tertile & 124 & 300 & $1.65(1.19-2.29)$ & $\mathbf{0 . 0 0 2}$ \\
Per tertile & & & $1.27(1.07-1.51)$ & $\mathbf{0 . 0 0 7}$ \\
\hline
\end{tabular}

${ }^{1}$ adjusted by age, sex, smoking status and alcohol use.

LTL as a uniform and strong predictor of pancreatic cancer [26]. One possible explanation for the inconsistent results should be the limited sample size (only 193 pancreatic cancer cases in Lynch's study and 331 cases in Campa's study). In current study, we also included TLV, which represents the heterogeneous telomere length across all chromosomal ends, as a candidate telomere feature. Consistent with our findings, Wang eT al [38] found TLV was strongly associated with an increased bladder cancer risk in Egyptian and the association was modulated by age. TLV measures the combined effects of very short and excessively long telomeres and represents a novel aspect 
of telomere function and might be a better biomarker for cancer risk.

In conclusion, this is the first study demonstrating that subjects with either short or extreme long telomeres may have an increased risk of pancreatic cancer in Asian population. Strengths in this study includes the prospective study design, the largest sample size, and the usage of TLV measure. The findings provided valuable clues for better understanding the underlying contribution of telomeres to carcinogenesis.

\section{MATERIALS AND METHODS}

\section{Study population}

The current study is part of the Cancer Prevention Study of Adolescent Population in Liaoning Province, China, since June 2010. This is a relatively large cohort of individuals who visit us for an annual check-up. Epidemiological survey was conducted using a structured questionnaire. Blood samples were collected at baseline recruitment and fractionated into serum, plasma, erythrocytes, and buffy coat from which DNA was extracted. Written informed consent for participation was obtained. Until Jan 2015, a total of 1,200 incident cases of pancreatic cancer and $\mathrm{CRC}$, which were histologically proven and available for Relative LTL assessment, were recruited. Patients who had a prior history of other cancers were excluded. For each case, the pathology reports were double-reviewed by either one of the two study pathologists. Matched controls were randomly selected from the cohort who were alive and free of cancer at the time the case was diagnosed.

\section{Measurement of relative LTL and TLV}

Genomic DNA was isolated from peripheral blood leukocytes using the QIAmp 96-spin blood protocol (Qiagen, Chatsworth, CA, USA). Relative LTL was determined using the real-time quantitative polymerase chain reaction (PCR) method. Using an Applied Biosystems 7900 Sequence Detection System, each sample was assayed in duplicate in separate 384-well plates. Relative LTL in genomic DNA was determined using the telomere (T) copy number to single-copy (S) b-globin (HGB) gene copy number. $\mathrm{T} / \mathrm{S}$ in this study is a relative and dimensionless value, which is proportional to the average telomere length per cell. For TLV measurement, first, blood lymphocyte cultures were set up following the protocol described previously [41]. Then, telomere length at each of the chromosomal ends was measured by telomere quantitative fluorescent in situ hybridization (TQ-FISH). After TQ-FISH, cells were analyzed using an epifluorescence microscope equipped with a charge-coupled device camera. Case and control samples were analyzed together in each batch. Laboratory personnel were blinded to participant characteristics and all assays were processed in triplicates.

\section{Statistical analyses}

All analyses were performed using SAS software (Version 9.3, SAS Institute Inc.). All statistical tests were two-sided, and $\mathrm{P}<0.05$ was considered statistically significant. The difference in the distribution of host characteristics between subjects groups was assessed by the Student's t-test for continuous variables, and the Pearson chi-square test for categorical variables. LTL measurements were log-transformed to obtain a variable with an approximately normal distribution. Relative LTL was categorized using the quartile in controls as cutoff points. Unconditional multivariate logistic regression was used to calculate odds ratio (ORs) and 95\% confidence intervals (CI) for the he strength of association between telomere features and the risk of pancreatic cancer and $\mathrm{CRC}$, adjusting for age, gender, smoking status, drinking status, hypertension, body mass index (BMI) and diabetes (where appropriate).

\section{FUNDING}

None.

\section{CONFLICTS OF INTEREST}

The authors declare that they have no conflicts of interest.

\section{REFERENCES}

1. Torre LA, Bray F, Siegel RL, Ferlay J, Lortet-Tieulent J, Jemal A. Global cancer statistics, 2012. CA Cancer J Clin. 2015; 65:87-108.

2. Siegel RL, Miller KD, Jemal A. Cancer statistics, 2015. CA Cancer J Clin. 2015; 65:5-29.

3. Long J, Luo GP, Xiao ZW, Liu ZQ, Guo M, Liu L, Liu C, Xu J, Gao YT, Zheng Y, Wu C, Ni QX, Li M, Yu X. Cancer statistics: current diagnosis and treatment of pancreatic cancer in Shanghai, China. Cancer Lett. 2014; 346:273-277.

4. Zheng R, Zeng H, Zhang S, Chen T, Chen W. National estimates of cancer prevalence in China, 2011. Cancer Lett. 2015.

5. Morran DC, Wu J, Jamieson NB, Mrowinska A, Kalna G, Karim SA, Au AY, Scarlett CJ, Chang DK, Pajak MZ, Oien KA, McKay CJ, Carter CR, et al. Targeting mTOR dependency in pancreatic cancer. Gut. 2014; 63:1481-1489. 
6. Harinck F, Canto MI, Schulick R, Goggins M, Poley JW, Fockens P, Kluijt I, Bruno M. Surveillance in individuals at high risk of pancreatic cancer: too early to tell? Gut. 2010; 59:1005; author reply 1006-1007.

7. Brand RE. Screening for familial pancreatic cancer: is doing something better than doing nothing? Gut. 2009; 58:1321-1322.

8. Ghaneh P, Costello E, Neoptolemos JP. Biology and management of pancreatic cancer. Gut. 2007; 56:1134-1152.

9. Poston GJ, Gillespie J, Guillou PJ. Biology of pancreatic cancer. Gut. 1991; 32:800-812.

10. Gudjonsson B, Livstone EM, Spiro HM. Cancer of the pancreas: diagnostic accuracy and urvival statistics. Cancer. 1978; 42:2494-2506.

11. Bruno MJ. Early diagnosis of pancreatic cancer; looking for a needle in a haystack? Gut. 2013; 62:955-956.

12. Skinner HG, Gangnon RE, Litzelman K, Johnson RA, Chari ST, Petersen GM, Boardman LA. Telomere length and pancreatic cancer: a case-control study. Cancer Epidemiol Biomarkers Prev. 2012; 21:2095-2100.

13. Hawk E, Patterson S. Modelling a dream: the molecular prevention of pancreatic cancer. Gut. 2010; 59:566-568.

14. Zhang C, Doherty JA, Burgess S, Hung RJ, Lindstrom S, Kraft P, Gong J, Amos CI, Sellers TA, Monteiro AN, Chenevix-Trench G, Bickeboller H, Risch A, et al. Genetic determinants of telomere length and risk of common cancers: a Mendelian randomization study. Hum Mol Genet. 2015; 24:5356-5366.

15. Walsh KM, Codd V, Rice T, Nelson CP, Smirnov IV, McCoy LS, Hansen HM, Elhauge E, Ojha J, Francis SS, Madsen NR, Bracci PM, Pico AR, et al. Longer genotypically-estimated leukocyte telomere length is associated with increased adult glioma risk. Oncotarget. 2015. doi: 10.18632/oncotarget.6468.

16. Schroecksnadel K, Ueberall F, Fuchs D. Telomere length abnormalities and human cancer. Clin Cancer Res. 2005; 11:860.

17. Nordfjall K, Larefalk A, Lindgren P, Holmberg D, Roos G. Telomere length and heredity: Indications of paternal inheritance. Proc Natl Acad Sci U S A. 2005; 102:16374-16378.

18. Peng S, Sen B, Mazumdar T, Byers LA, Diao L, Wang J, Tong P, Giri U, Heymach JV, Kadara HN, Johnson FM. Dasatinib induces DNA damage and activates DNA repair pathways leading to senescence in non-small cell lung cancer cell lines with kinase-inactivating BRAF mutations. Oncotarget. 2015. doi: 10.18632/oncotarget.6376.

19. Braumuller H, Wieder T, Brenner E, Assmann S, Hahn M, Alkhaled M, Schilbach K, Essmann F, Kneilling M, Griessinger C, Ranta F, Ullrich S, Mocikat R, et al. T-helper-1-cell cytokines drive cancer into senescence. Nature. 2013; 494:361-365.
20. Mathon NF, Lloyd AC. Cell senescence and cancer. Nat Rev Cancer. 2001; 1:203-213.

21. Holliday R. Cancer and cell senescence. Nature. 1983; 306:742.

22. Ellehoj H, Bendix L, Osler M. Leucocyte Telomere Length and Risk of Cardiovascular Disease in a Cohort of 1,397 Danish Men and Women. Cardiology. 2016; 133:173-177.

23. Zhan Y, Song C, Karlsson R, Tillander A, Reynolds CA, Pedersen NL, Hagg S. Telomere Length Shortening and Alzheimer Disease-A Mendelian Randomization Study. JAMA neurology. 2015; 72:1202-1203.

24. Xie Z, Jay KA, Smith DL, Zhang Y, Liu Z, Zheng J, Tian $\mathrm{R}$, Li H, Blackburn EH. Early telomerase inactivation accelerates aging independently of telomere length. Cell. 2015; 160:928-939.

25. Tellechea M, Gianotti TF, Alvarinas J, Gonzalez CD, Sookoian S, Pirola CJ. Telomere length in the two extremes of abnormal fetal growth and the programming effect of maternal arterial hypertension. Scientific reports. 2015; 5:7869.

26. Tanday S. Pattern of change in telomere length: possible predictor of cancer. Lancet Oncol. 2015; 16:e267.

27. Sun Y, Zhang L, Zhao L, Wu X, Gu J. Association of leukocyte telomere length in peripheral blood leukocytes with endometrial cancer risk in Caucasian Americans. Carcinogenesis. 2015; 36:1327-1332.

28. Campa D, Mergarten B, De Vivo I, Boutron-Ruault MC, Racine A, Severi G, Nieters A, Katzke VA, Trichopoulou A, Yiannakouris N, Trichopoulos D, Boeing H, Quiros JR, et al. Leukocyte telomere length in relation to pancreatic cancer risk: a prospective study. Cancer Epidemiol Biomarkers Prev. 2014; 23:2447-2454.

29. Lynch SM, Major JM, Cawthon R, Weinstein SJ, Virtamo J, Lan Q, Rothman N, Albanes D, Stolzenberg-Solomon RZ. A prospective analysis of telomere length and pancreatic cancer in the alpha-tocopherol beta-carotene cancer (ATBC) prevention study. Int J Cancer. 2013; 133:2672-2680.

30. Wang H, Wang Y, Kota KK, Kallakury B, Mikhail NN, Sayed D, Mokhtar A, Maximous D, Yassin EH, Gouda I, Sobitan A, Sun B, Loffredo CA, Zheng YL. Strong association between long and heterogeneous telomere length in blood lymphocytes and bladder cancer risk in Egyptian. Carcinogenesis. 2015; 36:1284-1290.

31. Engelhardt M, Drullinsky P, Guillem J, Moore MA. Telomerase and telomere length in the development and progression of premalignant lesions to colorectal cancer. Clin Cancer Res. 1997; 3:1931-1941.

32. Gao K, Li G, Qu Y, Wang M, Cui B, Ji M, Shi B, Hou P. TERT promoter mutations and long telomere length predict poor survival and radiotherapy resistance in gliomas. Oncotarget. 2015. doi: 10.18632/oncotarget.6007.

33. Heidenreich B, Rachakonda PS, Hosen I, Volz F, Hemminki K, Weyerbrock A, Kumar R. TERT promoter 
mutations and telomere length in adult malignant gliomas and recurrences. Oncotarget. 2015; 6:10617-10633. doi: 10.18632/oncotarget.3329.

34. Pezzolo A, Pistorio A, Gambini C, Haupt R, Ferraro M, Erminio G, De Bernardi B, Garaventa A, Pistoia V. Intratumoral diversity of telomere length in individual neuroblastoma tumors. Oncotarget. 2015; 6:7493-7503. doi: 10.18632/oncotarget.2115.

35. Yoon JH, Seo HS, Choi WS, Kim O, Nam SW, Lee JY, Park WS. Gastrokine 1 induces senescence and apoptosis through regulating telomere length in gastric cancer. Oncotarget. 2014; 5:11695-11708. doi: 10.18632/ oncotarget.2586.

36. Pitman RT, Wojdyla L, Puri N. Mechanism of DNA damage responses induced by exposure to an oligonucleotide homologous to the telomere overhang in melanoma. Oncotarget. 2013; 4:761-771. doi: 10.18632/ oncotarget.1047.

37. Wentzensen IM, Mirabello L, Pfeiffer RM, Savage SA. The association of telomere length and cancer: a meta-analysis. Cancer Epidemiol Biomarkers Prev. 2011; 20:1238-1250.
38. Kobitsu K, Tsutsumi M, Tsujiuchi T, Suzuki F, Kido A, Okajima E, Fukuda T, Sakaki T, Konishi Y. Shortened telomere length and increased telomerase activity in hamster pancreatic duct adenocarcinomas and cell lines. Mol Carcinog. 1997; 18:153-159.

39. van Heek NT, Meeker AK, Kern SE, Yeo CJ, Lillemoe KD, Cameron JL, Offerhaus GJ, Hicks JL, Wilentz RE, Goggins MG, De Marzo AM, Hruban RH, Maitra A. Telomere shortening is nearly universal in pancreatic intraepithelial neoplasia. Am J Pathol. 2002; 161:1541-1547.

40. Willeit P, Willeit J, Mayr A, Weger S, Oberhollenzer F, Brandstatter A, Kronenberg F, Kiechl S. Telomere length and risk of incident cancer and cancer mortality. Jama. 2010; 304:69-75.

41. Zheng YL, Loffredo CA, Yu Z, Jones RT, Krasna MJ, Alberg AJ, Yung R, Perlmutter D, Enewold L, Harris CC, Shields PG. Bleomycin-induced chromosome breaks as a risk marker for lung cancer: a case-control study with population and hospital controls. Carcinogenesis. 2003; 24:269-274. 